
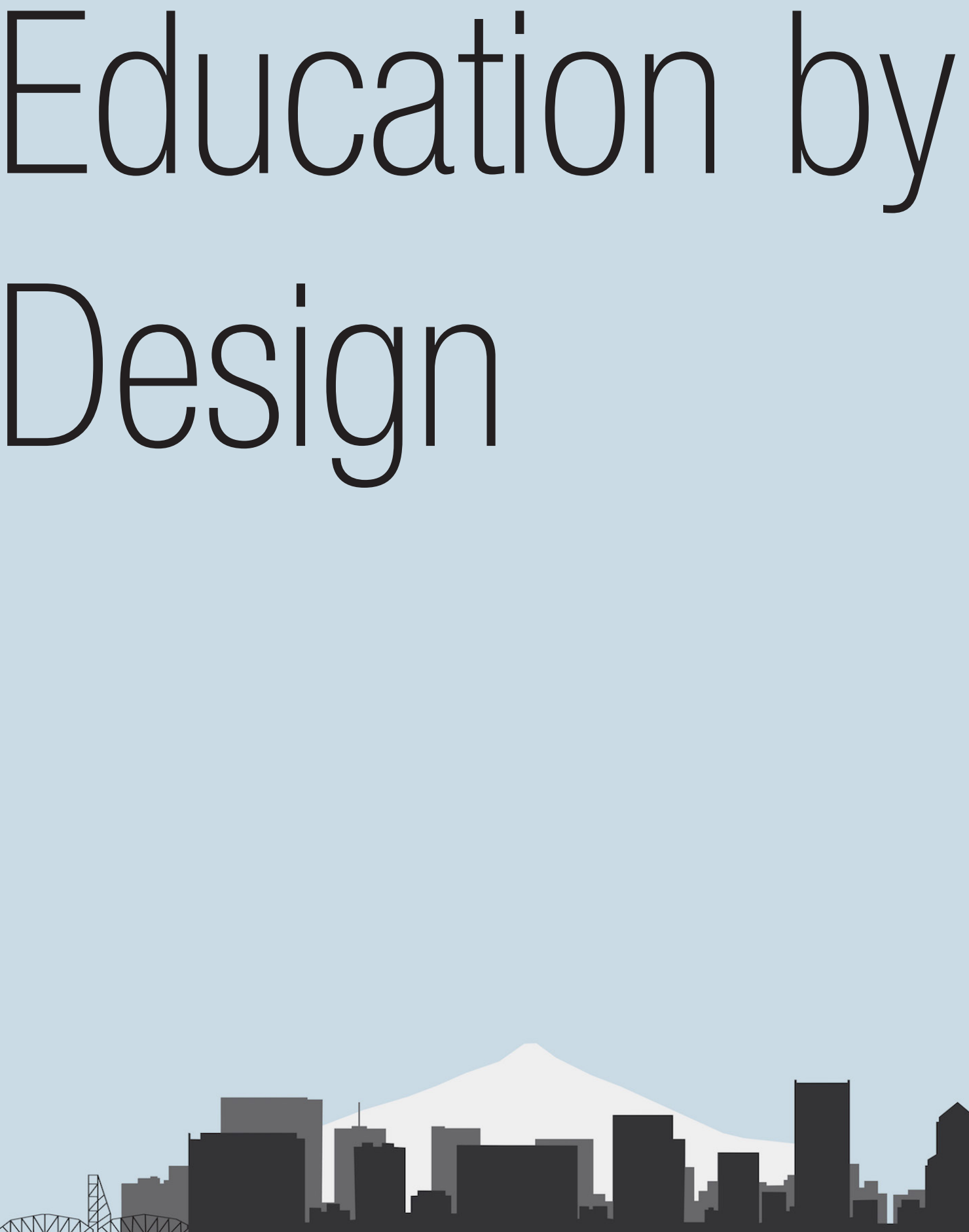

2019 Reynolds Symposium: Education by Design October 18-20, 2019 


\section{Organizing Committee:}

[co-organizers]

Professor Alison Kwok, Ph.D, FAIA, University of Oregon

Emeritus Professor John Reynolds, FAIA, University of Oregon

\section{[Symposium coordinator]}

Isabel Rivera, Ph.D., University of Oregon

Professor Walter Grondzik, P.E., Ball State University

Professor Bruce Haglund, AIA Assoc., University of Idaho

Assistant Professor Emily McGlohn, AIA, Auburn University

Associate Professor Ulrike Passe, lowa State University

Assistant Professor Siobhan Rockcastle, Ph.D., University of Oregon

Sharon Refvem, FAIA, LEED Fellow, Senior Associate and Director, Sustainability Resource Group, Hawley Peterson Snyder 


\title{
When Performance Informs Design
}

\author{
Sandy Stannard, RA, LEED AP \\ Professor \\ California Polytechnic State University \\ San Luis Obispo, California \\ stannard@calpoly.edu
}

\begin{abstract}
It is clear that building energy performance plays an essential role in architecture and in architectural practice, not only for reasons of occupant comfort and energy efficiency but also for minimal code compliance. While achieving energy compliance is essential and even laudable, our current definition of "building performance" is somewhat limited. ${ }^{1}$ Energy performance analyses are often performed solely for code compliance with a minimal feedback loop during the design process. In the instances when analyses are completed as part of design, a growing array of simulation tools allow designers to make more informed decisions during the design process. There is tremendous potential in this trajectory.

The use of parametric and other performance analysis tools to help design professionals simultaneously achieve superior performance as well as delightful aesthetics represents an emerging chapter in the design professions. This paper will highlight a handful of sample undergraduate thesis and design/build projects which focused on the investigation of performative material systems as part of a larger design challenge. In each of these examples, "performance" went beyond the prosaic. Instead, these projects identified a particular environmental necessity based on the project situation (the need for water, the need for cleaner air; and so on). Inspired by natural systems or by emerging materials engineering, the students used multi-modal methods to explore their design ideas (parametric digital models; physical models at multiple scales; simple as well as complex math; and so on), ultimately resulting in an enhanced performative system that in turn influenced overall building form. In each case, it was performance that informed design, while simultaneously striving to appeal to the senses through an exploration of beauty.
\end{abstract}

\section{THE SITUATION}

Historically, there is no question that the essential relationship between vernacular architecture and building performance was necessary for survival, particularly in more extreme environments. One needs only to study traditional building methodologies around the world to appreciate the practical yet profound manipulation of building form and available materials designed to work symbiotically with local climate.

With the coincident rise of modernism and the technologies that supported multi-story buildings (elevators, mechanical comfort systems, electric lighting), building design in general failed to incorporate aspects of the essential collective wisdom inherent in vernacular design, particularly lessons related to building performance (in particular, thermal and luminous comfort). One distinct example of this shift is revealed through an investigation of Le Corbusier's Cité de Refuge. In the 1933 construction of the project, the multiple story building included a single-glazed southern facing façade designed with a purist aesthetic. The result was intense overheating and occupant discomfort that ultimately required a 1952 addition of an external shading device (brise soleil) and operable windows (Diaz and Southall 2015). While scholars speculate whether the inspiration for Le Corbusier's brise soleil may have come from vernacular Brasilian architecture (an argument beyond the scope of this paper), the original as-built Cité de Refuge highlights the preferencing of design aesthetics over thermal performance. This might lead us to consider a generalized question in the area of architectural design thinking: does form and aesthetic decision-making take precedence over performance considerations, or is it possible that performance

${ }^{1}$ For the duration of this paper, the term "building performance" or simply "performance" will be used, with the intended focus on building energy performance and resource use. 
might inform design? And if performance can more overtly inform design, can it be achieved in a manner that is also delightful to the human user?

This is a question explored by a handful of undergraduate architecture thesis projects and one design|build example at the California Polytechnic State University. A required undergraduate architectural thesis course is offered in the fifth year of Cal Poly's five year BArch program; students conceive of independent design projects and work on these proposals over three consecutive quarters. Students enter the course with varying degrees of expertise with digital tools. As the individual projects are distinct, tool selection and use is tailored to the respective challenge (at times resulting in group workshops and/or independent learning). The author works with 18-20 thesis students each year, under the topical umbrella of "Architecture + Nature." Each student proposal is unique and presents its own particular set of design challenges.

The method of how performance might inform or inspire design decision-making requires clarification. In this case, the method described here is more exploratory than the industry term of "performance based design ["PBD," which is the iterative process of testing design performance. It should be noted that each of the examples illustrated here also included iterative whole building energy analyses as part of the design process; this part of the design process will not be presented in detail here.

In the cases presented in this paper, performance led the design process. The first step in this process was identifying the primary issue or issues at the core of the project situation; the examples here revolved around particular environmental challenges. In each case, the environmental issues represented a challenge that could benefit from mitigation or maximization. In this way, the method these students used is more akin to what Ken Yeang identifies as an "ecological approach:"

There are fundamental differences between an engineering approach to green or ecodesign and the ecological approach. In the engineering approach, the designer begins with the end, a picture of the desired outcome governed by the process of efficiency, and ends with the goal of production. In contrast, the ecological design approach begins with environmental discernment (ie, seeing what there is) and is governed by the process of achieving environmental harmony (Yeang 2006, 24).

The students then employed their investigative and design sensibilities through the use of a multiplicity of tools, from the digital to the analog. This multi-modal workflow allowed students to explore their chosen environmental issue(s); these explorations in turn informed micro as well as macro design decisionmaking. The use of parametric tools in particular fueled this method. These tools can help designers simultaneously achieve superior performance as well as delightful aesthetics.

While providing the initial inspiration for decision-making, performance was not the only goal of these projects. Creating simultaneously functional as well as beautiful responses remained at the core of each proposal, responding to the charge of Sim van der Ryn (among others):

Where has beauty gone? Since our emergence as a species, humans have been making places and space. We've been designing them for the last thirty thousand years. All that practice has made us better at producing more material things, and doing it faster and cheaper. Our advancements in science and technology have provided the knowledge and tools that have allowed us to shape the material world in utterly fantastic ways. But we have lost our ability to create places of beauty, comfort, and durability that fit both the natural world and our own human nature (Van der Ryn 2005, 7).2

With these goals in mind, each student example will be presented in turn.

${ }^{2}$ While pursuing "beauty" was a goal for each of the examples in this paper, beauty is not a metric that can be measured in a scientific way. As designers, we aspire to beauty; the beholder ultimately decides if it was achieved. 


\section{Issue: Air Quality}

Andrew chose a project site in Fresno, California, a city that has among the worst air quality in the nation. For Andrew, the question in this case revolved around how an architectural intervention might begin to mitigate poor air quality. The bottom line was a design that did not add to the problem. Then began an investigation into the potential for the building to demonstrate an alternative way forward (an active rather than passive approach).

Andrew began studying the potential for the building skin to act as a purifying device. He researched the experimental use of titanium dioxide as a coating (a product called ProSolve 370e), which, in the presence of ambient daylight, reduces NOx (combined nitrogen dioxide and nitric oxide) and VOC (volatile organic compound) pollutants to harmless amounts of carbon dioxide and water (Prosolve370e, n.d.). Given this choice of material as a design response, Andrew thus focused on the NOx and ozone (of which VOCs are a precursor) data for Fresno. 3 He quickly realized that maximizing the surface area of the exterior building skin was critical for his design response. 4 He looked to nature for sources of inspiration for the design of that skin, keeping in mind that he also needed to simultaneously maintain ventilation and views.

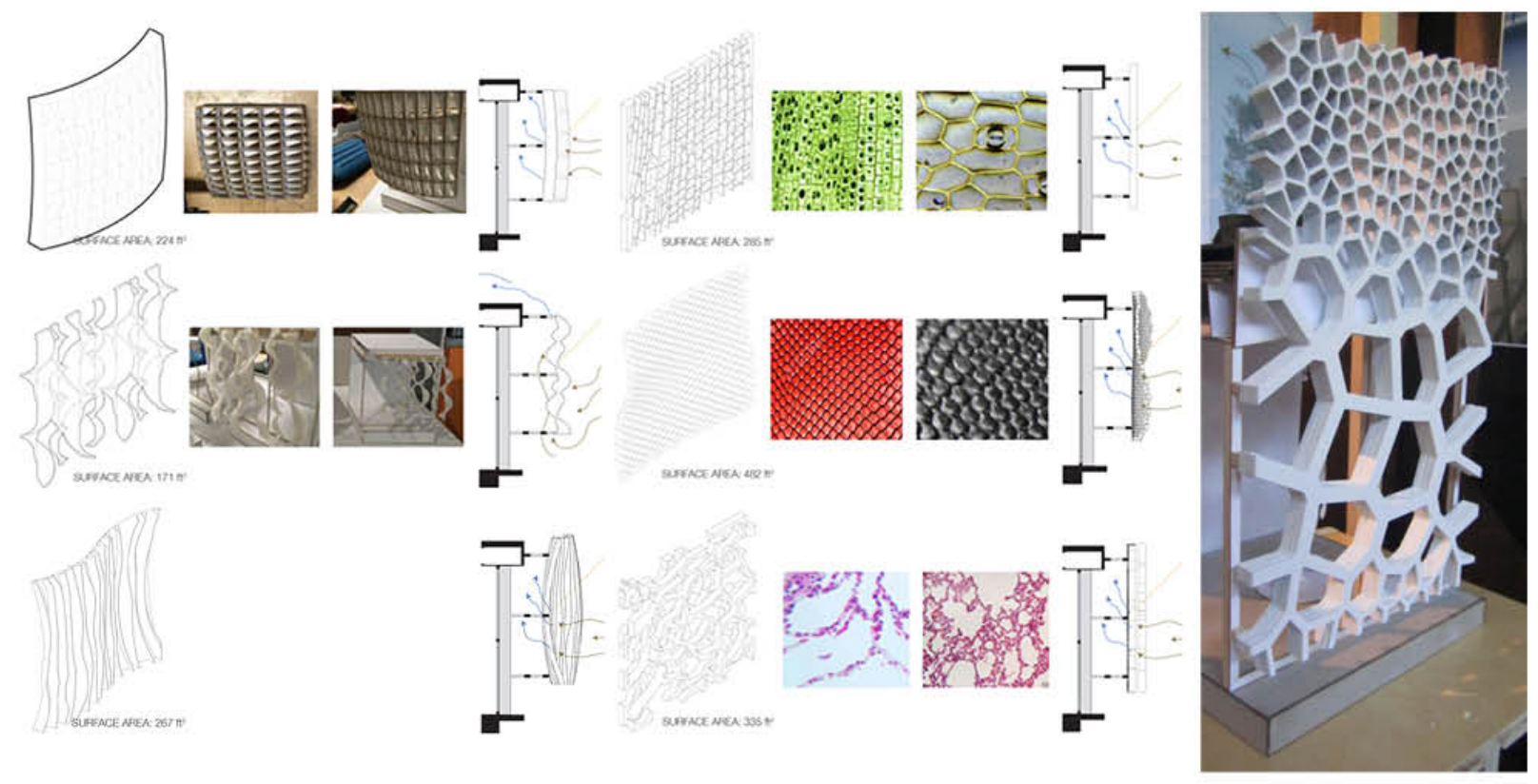

Figure 1. Air pollution mitigation skin studies. Student: Andrew Valles, 2017

Andrew's investigations led him to study plant cells, snake skin and lung cells, along with pure geometric formations (perforations, spirals; see Figure 1). While the snake skin provided him the most surface area, it provided no opportunity for light and air. Instead, he ultimately chose a combination of his test systems, somewhere between the lung and plant cell inspirations. Throughout his design process, he worked back and forth from digital to physical, using Rhino and Grasshopper to parametrically optimize the surface area while also maintaining critical openings and of course continually seeking beauty.

3 Measured ozone in Fresno ranges from .108 - .135 ppm, exceeding the maximum .070 ppm (CA) and .075 ppm (U.S.) over an 8 hour period. Measured NO2 in Fresno ranges from .034-.077 ppm over a 1 hour period (compared .18 ppm (CA) and $0.1 \mathrm{ppm}$ (U.S.) over a 1 hour period (City of Fresno).

4 Given the proprietary nature of the Prosolve material, Andrew was unable to precisely calculate the magnitude of his mitigation proposal, apart from maximizing surface area and exposure to daylight. 


\section{Issue: Water}

As a native of Jordan, Shereen was intimately aware of the issue of water scarcity. The natural supply of Jordanian fresh water does not match the demand, leading to the extraction of water from unsustainable sources. In addition, in Shereen's project site in Aqaba, ninety-five percent of the city's rainwater is lost to evaporation due to the climate. She chose to investigate how the exterior skin of her design project could act as a water collector for atmospheric water. Like Andrew, Shereen drew inspiration from nature for her design investigations. Spider webs, cacti, beetles, mosses: all collect water in resourceful and inspiring ways. Her studies revealed the following collection methods: the desert moss uses leaf tip "awns;" the cactus utilizes cone shaped spines; the spider silk employs hydrophilic nanofibrils; and the beetle capitalizes on hydrophilic bumps. Through translating then modeling each of these systems discreetly at human and building scales, Shereen $3 \mathrm{~d}$ modeled, printed and calculated the surface area for each study. She then hybridized the desert moss and beetle inspired studies to create a skin designed to capture and collect atmospheric water (Figure 2). 5

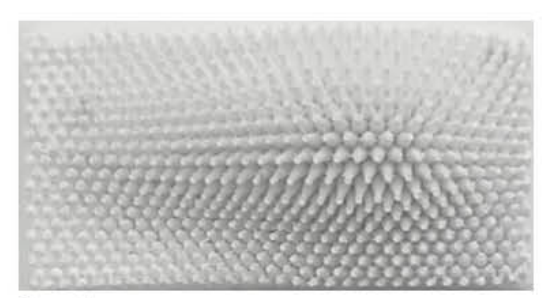

desert moss

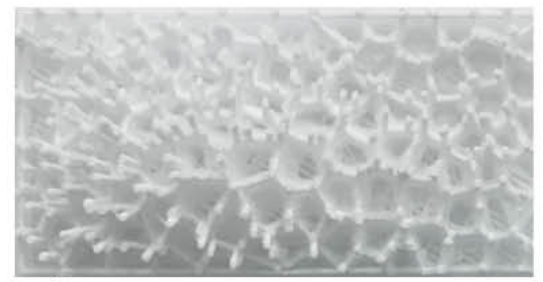

cactus

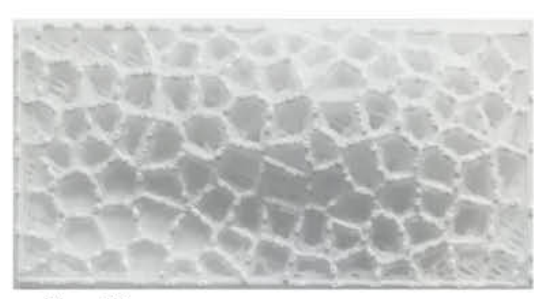

spider silk

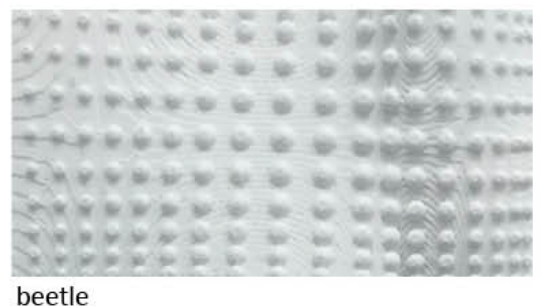

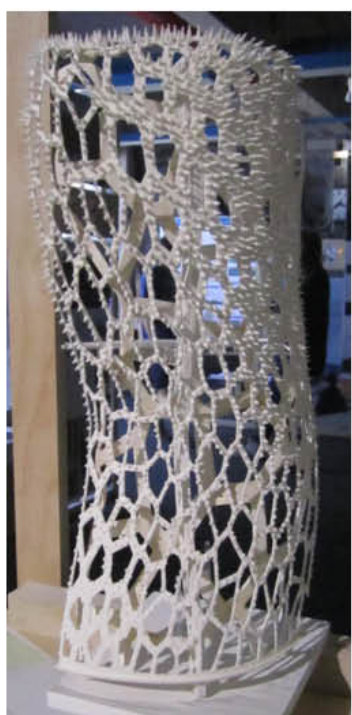

Figure 2. Water collection skin studies. Student: Shereen Ghishan, 2017

\section{Issue: Clean Power}

Eric chose a project site in Guangzhou, China, which has a serious air pollution problem. His site demanded a high-rise response and yet (similar to Andrew) he did not want the project to compound to the city's air pollution challenges. Rather, Eric aimed his response at the source of the air pollution: power production, which is predominantly coal-based in Guangzhou. Eric aimed to provide an emblematic solution through an alternative form of power generation. After completing an intensive analysis of this very wet climate (66 inches/year of rainfall) and the electric potential embodied in that falling water, Eric chose to employ the use of piezoelectric technology to generate power for the project. He intended for the building to generate electricity from the vibrational energy of raindrops striking an array of piezoelectric films integrated into the building's skin. He calculated that this technology would generate about one third of the energy of his 50-story project. He further proposed that the water could then be re-purposed for use on site.

5 Due to the complexity of the proposal (and the undergraduate nature of the thesis), Shereen was unable to calculate precisely how much water her building skin design proposal might collect. 


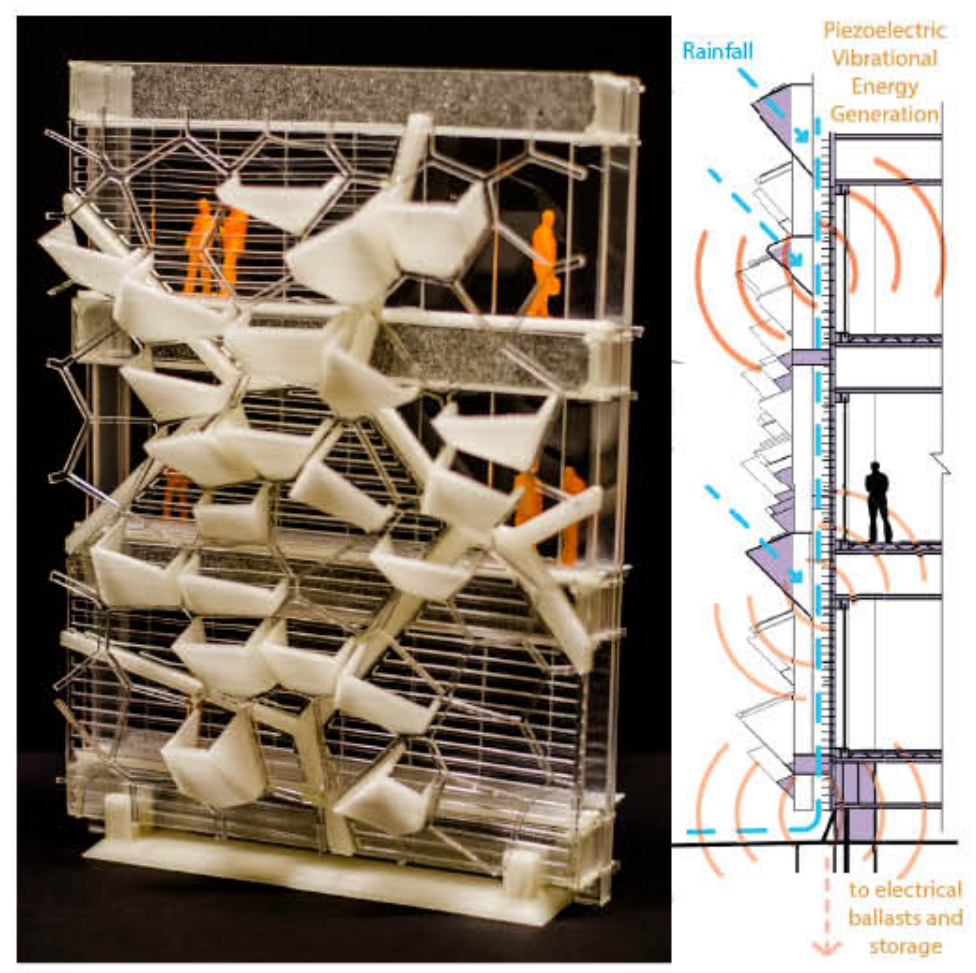

Figure 3. Piezoelectric power skin studies. Student: Eric Burford, 2017

In addition to the use of Rhino for general design studies; hand calculations to confirm overall capacity; and $3 \mathrm{~d}$ printing as well as other physical models for proof of concept (Figure 3), some of the more unusual tools that Eric used to develop his design solution included:

- APC Piezo Calculator: to calculate the piezoelectric potential of the individual pieces (APC International, Ltd, n.d.).

- WUFI for studying the maximization of a drop of rainwater (Oakridge National Laboratory, n.d.).

- Autodesk's Flow Design to create a surface that would funnel rain at an appropriate angle without crowding any neighboring collectors.

- Grasshopper for structural iterations, balancing the necessities of securing the piezoelectric screen, carrying necessary building loads and eliciting delight. 


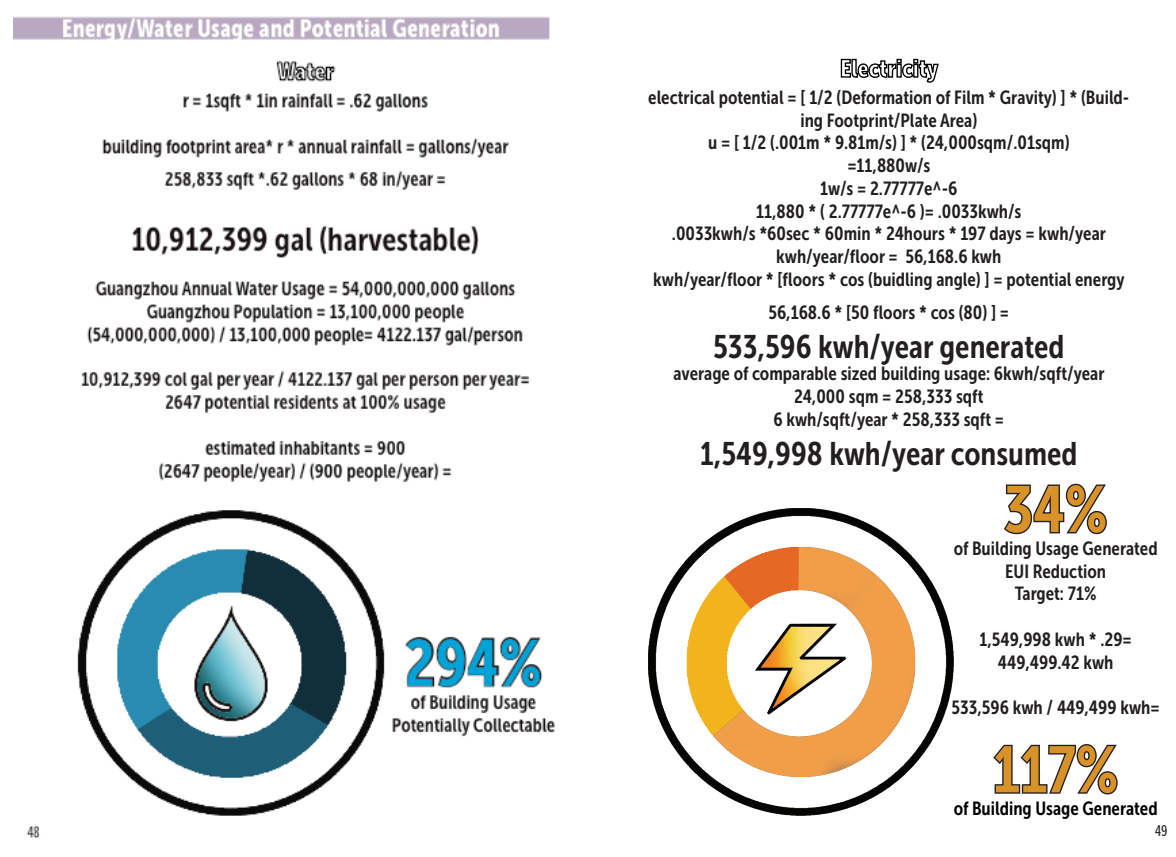

Figure 4. Water and Electricity Calculations. Student: Eric Burford, 2017

By employing a multiplicity of tools, both analog and digital, Eric was able to transcend the hypothetical, producing a robust design proposal demonstrating how harnessing the energy potential of a raindrop can inform a full-scale building design while simultaneously appealing to the senses (Figure 4).

\section{Issue: Thermal Control and Comfort}

We also used similar methodologies in our work on Cal Poly's Solar Decathlon 2015 project, INhouse. 6 Without exhaustively describing the entire project, this paper will highlight a handful of design responses relating to thermal control and thermal comfort.

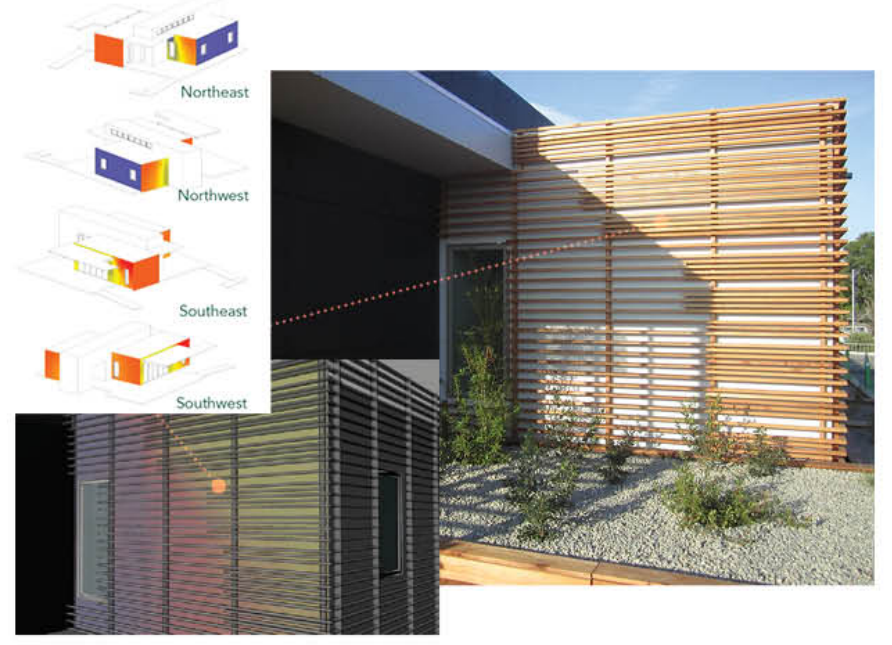

Figure 5. INhouse climatically responsive redwood screen design. Solar Cal Poly, 2015

${ }^{6}$ Additional information about INhouse can be found at these two sites:

http://www.calpolysolardecathlon.org/; https://www.solardecathlon.gov/2015/index.html 
Understanding the intense climate of the Irvine competition site, we knew that shading was an essential climatic design response, including shading the building skin. While cladding and skin design are part of any architectural project, deploying the skin in a deliberate, tuned, responsive manner (that could also serve as an educational vehicle) was our goal. We created a composite map of incident solar radiation on each of the building's faces. With this information, we then "tuned" the redwood screen that was part of the skin design to precisely shade the envelope during the most extreme conditions. Such tuning also ensured the maximized use of the redwood; in this case the screen was not only aesthetic but also performative. In addition, the screen also represented a "heat map" of the environmental forces acting on the building skin (Figure 5). Thus, the climate data directly informed our design response: performance informing design.

An additional issue to meet our climatic responsive design goals for INhouse was providing adequate thermal mass to dampen internal diurnal temperature swings. Thermal mass is generally heavy; we needed to be weight conscious in the transportation of the project to and from the competition site. For this project, we chose to work with phase change material (PCM), some invisible inside a "phase change duct" running through the core of the house and some visible in an artistic screen. As an interactive piece, the visible PCM was designed as a decorative screen in order to make visible the performance of the building: the PCM tiles "freeze" and "melt" at roughly $70^{\circ} \mathrm{F}$, making visible the heat exchange capabilities of the bio-based oil inside the tiles (Figure 6).

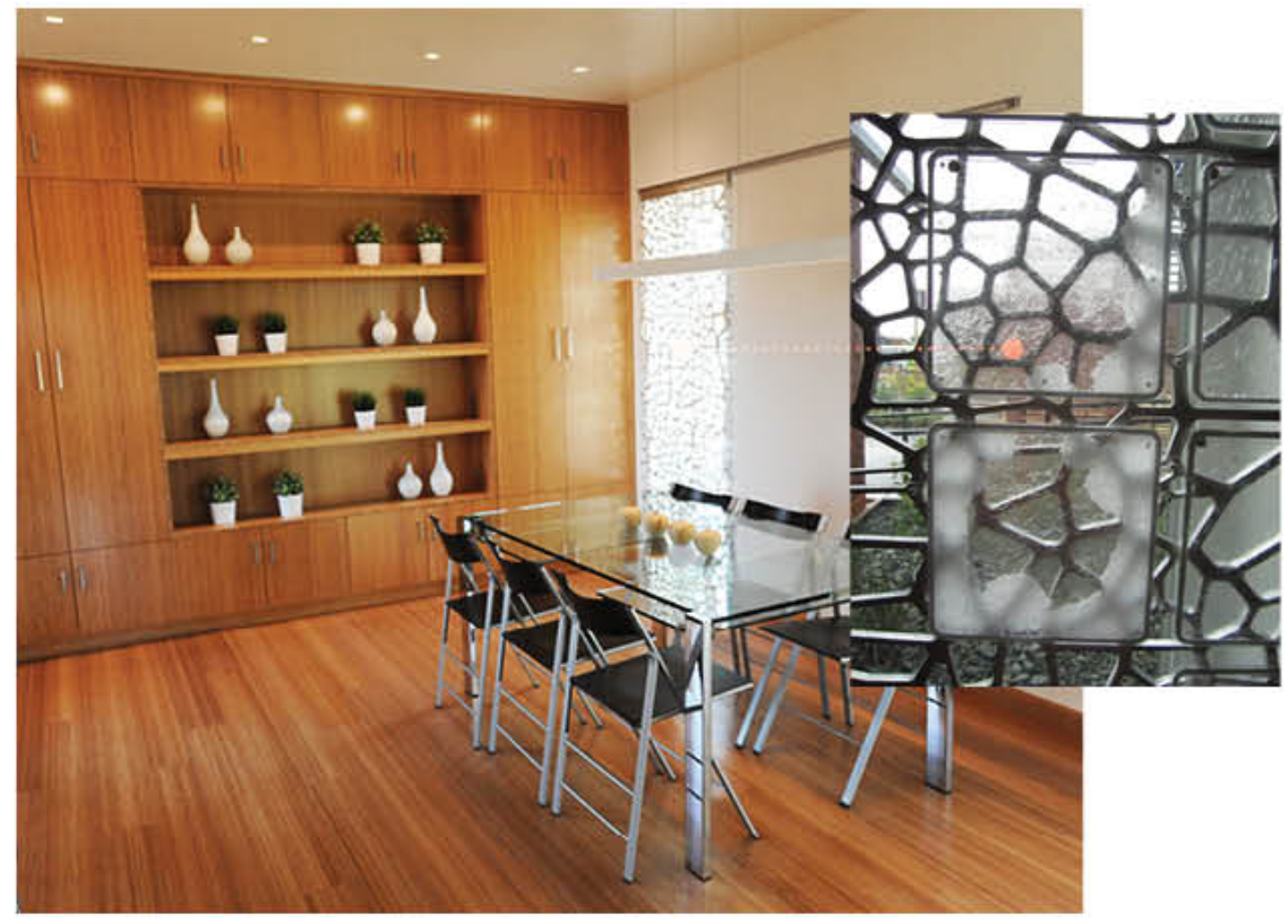

Figure 6. INhouse phase change material (PCM) screen design. Solar Cal Poly, 2015

\section{MAKING AN ECOLOGICAL U-TURN \\ (inspired by environmentalist David Brower)}

This shifts the complexity of architecture from its frequently belabored preoccupation with the visual composition of a shape alone, to the actual behaviors and outcomes of a particular architectural formation. Both are as interesting and compelling as ever, especially when developed together. Therefore, an architect's consideration of formation might begin finally to reflect the degree to which its performance engenders complex adaptive effects of its formation (Moe 2013, 291). 
The aim of the examples offered in this paper is to demonstrate a methodology: identifying an ecological issue and then using contemporary tools (particularly parametric analyses) to help us discover responsive design solutions. In this way, perhaps we can learn how performance can inform design in a way that is not just solving a problem but that also strives to appeal to the senses through an exploration of beauty.

The examples described here are relatively modest in scope and are predominantly speculative (with the exception of the design|build example). However, the method of "performance informing design" is repeatable and scalable. In an unselfconscious way, a version of this method is visible in many examples of vernacular architecture. In contemporary architectural practice, design firms dedicated to investigating ecologically responsive design solutions inspire us with performative design approaches. In the examples illustrated here, from larger issues (such as the air, water, and power examples), ecologically-minded performative design thinking can be at the scale of a building or a building skin. As demonstrated with the INhouse example, the method can be employed in a more discreet manner, focusing on particular design components (such as the thermally responsive PCM screen) within the scope of a larger project.

As thoughtful, educated designers, we are the stewards not only of creating meaningful spaces for people but also for respecting the environmental setting of these places. We have the opportunity to employ contemporary design tools and methods to fully explore the potential for performative interdependent relationships between a given situation and its inhabitants. Using this methodology, we might reach the goal of achieving a fitting co-existence, a symbiotic relationship that does not impoverish and perhaps even enhances the planet as well as our human experience.

While the human animal is the most polluting one in nature, it is also the only species that has the capability to plan and manage its own future. It is this capability..... that must be effectively exercised now (Yeang 2006, 18).

\section{REFERENCES}

APC International, Ltd. “APC Piezo Calc.” Accessed 5/29/29. https://www.americanpiezo.com/knowledge-center/apc-piezo-calc.html.

City of Fresno, 2014. Master Environmental Impact Report - Air Quality. Accessed 8/13/19. https://www.fresno.gov/darm/wp-content/uploads/sites/10/2016/11/Sec-05-O3-Air-QualityMEIR.pdf

Diaz, L.M. and Southall, 2015. Le Corbusier's Cité de Refuge: Historical and Technological Performance of the Air Exacte. Valencia: LC 2015 - Le Corbusier, 50 Years Later.

Moe, Kiel, 2013. Convergence: An Architectural Agenda for Energy. New York: Routledge.

Oak Ridge National Laboratory. "Innovation in Buildings.” Accessed 5/29/19. https://web.ornl.gov/sci/buildings/tools/wufi/.

Prosolve307e. “A Pollution Eating Façade Module.” Accessed 5/29/19. http://www.prosolve370e.com/.

Van der Ryn, Sim, 2005. Design for Life. Layton, Utah: Gibbs Smith.

Yeang, Ken, 2006. EcoDesign: A Manual for Ecological Design. London: John Wiley + Sons. 